\title{
Are the Market Effects Associated with Revisions to the TSE300 Index Robust?*
}

\author{
Richard Chung \\ Concordia University, Canada \\ Lawrence Kryzanowski \\ Concordia University, Canada
}

This article examines the stock market effects of changes in the composition of the TSE300 index over the period 1990-94. The test methodology adjusts for thin trading, pre- and post-revision abnormal performance and sample selection criterion effects. The models used to characterize returns include factors such as illiquidity and large trade activity. The positive and transitory median changes in traded volumes become insignificant when market-adjusted volumes are examined. No permanent effects on trade and analyst price behavior are identified. Traditional market-adjusted abnormal return inferences are not robust. The announcement window abnormal returns are smaller for annual versus non-annual index additions. This suggests that a longer advance notice period more than compensates for a larger number of simultaneous index revisions. The findings support the price pressure and liquidity hypotheses. Temporary changes in liquidity costs temporarily move stock prices from their equilibrium values, and announcement window abnormal returns are essentially reversed in subsequent periods (JEL G14).

Keywords: index revision, abnormal returns, liquidity, event study.

\footnotetext{
*Financial support from FCAR (Fonds pour la formation de chercheurs et l'Aide à la Recherche), SSHRC (Social Sciences and Humanities Research Council of Canada) and the Concordia FRDP (Faculty Research and Development Programme) are gratefully acknowledged. We appreciate comments and suggestions by Yakov Amihud, Didier Davydoff, Lawrence Harris, Robert Korajczyk, Jean Masson, Rene Stulz, Bob Whaley, and the participants at presentations at the Northern Finance Association (Quebec City 1996), SBF-Bourse de Paris (Paris 1996) and TD Quantitative Capital Spring Seminar (Ottawa 1997), and the University of Manitoba and Laval University. We appreciate the research assistance provided by Pei Shuo Chen, the analyst data supplied by I/B/E/S Inc., and information on index funds provided by Marcia Brown and Dominic Clermont of TD Asset Management Inc., Rick Drennan of Benefits Canada, Gordon Garmaise of Garmaise Investment Technologies Inc., Morgan McCague of Ontario Teachers' Pension Plan Board, Michel Nadeau of the Caisse de dépôt et du placement du Québec, and Rajiv Silgardo of BZW Barclays Global Investment. All remaining errors are the authors' responsibility.
}

(Multinational Finance Journal, 1998, vol. 2, no. 1, pp. 1-37)

(C) Multinational Finance Society, a nonprofit corporation. All rights reserved. DOI: $10.17578 / 2-1-1$ 


\section{Introduction}

Since October 1989, Standard and Poor's (S\&P's) policy is to announce changes to the S\&P500 index one week prior to their implementation. For changes during approximately the first five years of this new policy, Beneish and Whaley (1996) and Lynch and Mendenhall (1997) document significantly positive (negative) post announcement abnormal returns that are only partially reversed following additions (deletions). ${ }^{1}$ Based on indirect evidence, Beneish and Whaley (1996) conclude that the S\&P's announcement practice has given rise to the 'S\&P game; which involves buying the shares of the added stocks ahead of S\&P500 funds and then selling after index demand is satisfied. Lynch and Mendenhall (1997) attribute their results to temporary price pressure and downward-sloping demand curves for stocks. They conclude that their results represent a violation of market efficiency which risk arbitragers should fully exploit on the announcement day.

Both studies do not adequately deal with the fact that historical returns for index replacement stocks are not representative of returns in general since the $\mathrm{S} \& \mathrm{P}$ replacement selection decision considers historical price information to select stocks for replacement. Edmister, Graham, and Pirie (1994) find that the selection criteria used by S\&P leads $S \& P$ to select stocks that have significant price increases relative to the market over a two-year period. This is referred to as the selection criteria effect. Similar sample selection criteria effects are addressed in studies of Value Line rank changes (Copeland and Mayers [1982]) and the winner-loser effect (Fama and French [1992] and Kryzanowski and Zhang [1992]) $)^{2}$. Beneish and Whaley (1996), p.1916, justify their decision not to estimate systematic risk and not to risk-adjust abnormal returns as "[w]hile theoretically it may be more correct to do so, Brown and Warner (1985) show that explicit risk-adjustment is unnecessary using event study methodologies on daily return data"3. Lynch and

1. The periods studied are October 1989 to June 1994 in Beneish and Whaley (1996) and March 1990 to April 1995 in Lynch and Mendenhall (1997).

2. The winner-loser effect is that over two contiguous number of years, winners in the first period become losers in the second period, and losers in the first period become winners in the second period.

3. According to Campbell, Lo, and MacKinlay (1997), p. 156, a "general recommendation is to use such restricted models [such as the market-adjusted-return model] only as a last resort, and to keep in mind that biases may arise if the restrictions [that the 
Mendenhall (1997), p.357, find slightly less positive (negative) abnormal returns for additions (deletions) based on market model parameter estimates using returns that end more than two years ( 872 to 673 days) prior to the announcement day. Vijh (1994), among others, shows that the betas based on daily returns of stocks added to the S\&P500 increase. Thus, it is not surprising that Lynch and Mendenhall report increasingly negative mean $C A R$ in the ten days up to the announcement day for index additions and positive mean $C A R$ thereafter.

Leamer (1983) and (1985) persuasively argues that the application of traditional econometric procedures to a given data set may lead to inferences that are not robust. Leamer advocates that the robustness of empirical results is assessed for alternate data sets and methodological procedures. The primary purpose of this paper is to test various alternative explanations of the market effects of revisions to a non-U. S. stock-market index, the Toronto Stock Exchange (TSE) 300 index, using daily data over the five-year period, 1990-1994. Like most of the market overreaction studies, this article uses a Jensen measure formulation that accounts for abnormal return behavior before, after and on the index revision announcement dates. The test methodology adjusts for thin trading and the sample selection criteria effects on each stock's market sensitivity and its changes, and incorporates various Fama-French-like factors (1992) such as illiquidity and large trade activity into the model used to characterize returns. ${ }^{4}$

The higher number of analysts following stocks and the higher consensus estimates of earnings per share or EPS growth for index additions are attributable to the selection criteria used by TSE index revisers when choosing index stock replacements or deletions and not to the revision events themselves. Large traders prefer to make their portfolio adjustments in the within-advance notice window for annual index additions and for nonannual deletions, and in periods other than the effective date window for annual (simultaneous) deletions. This finding differs markedly from that reported by Lynch and Mendenhall

market model intercept and beta are constrained to be 0 and 1, respectively] are false".

4. For Canadian stocks, Chung and Kryzanowski (1997b) find a highly significant conditional relationship between returns and betas (like Pettengill, Sundaram, and Mathur (1995) for U.S. stocks), and no significant relationship between returns and size and/or bookto-market equity (unlike Fama and French (1992) for U.S. stocks). Chung and Kryzanowski find that betas and illiquidity jointly capture the cross-sectional variation in average stock returns (à la Amihud and Mendelson (1986) for U.S. stocks). 
(1997) for S\&P500 inclusions where the greatest relative trading activity occurs on the day before the effective date. This paper finds strong evidence that TSE300 index revisions have a temporary but no permanent effect on measures of trade.

While the price effect inferences for the TSE300 are similar to those drawn for the S\&P500 by Beneish and Whaley (1996) and Lynch and Mendenhall (1997) for market-adjusted returns, the inferences are not robust. When the sample selection criteria effect of index revisions on the models used to calculate abnormal returns is accounted for, ${ }^{5}$ this article finds that index revision announcements cause significant abnormal returns with the expected sign for the announcement window for both types of index additions and for annual index deletions. These significant abnormal returns are economically small (less than 60 basis points) for annual index additions and deletions that become effective up to a month after being first announced. They are economically large (over 300 basis points) for nonannual index additions that become effective within a few days after being first announced. The Jensen measure of abnormal performance is not significant for index additions and deletions when performance is measured from the announcement date onwards. Thus, the evidence presented herein supports the pricepressure hypothesis and not the imperfect substitutes hypothesis.

The remainder of this article is organized as follows. In the next section, a further rationale is presented for an examination of the price effects of revisions to the TSE300 index. In the third section, five possible explanations or hypotheses for price movements around index change dates are discussed. The fourth section describes the sample and data studied herein. Section five presents and analyzes the empirical results. Section six concludes with a brief summary of the major results and conclusions.

\section{Rationale for Examining Revisions to the TSE300 Index}

As discussed in appendix A, the TSE300 index is a float-capitalizationweighted index. The index is revised as required as existing members

5. Since the primary TSE300 index revision criterion is market value of equity, stocks going into and out of the index tend to have significant price increases and decreases, respectively, relative to the market over at least the prior calendar year. 
of the index are parties to mergers, acquisitions, other corporate reorganizations and failure, and annually to better reflect the changing investment opportunity set available to domestic investors ${ }^{6}$. Since 1989, the TSE announces forthcoming annual revisions prior to their effective dates. See appendices A and B for greater details on the TSE300 index and its comparison with the S\&P500 index, and on the implementation and substantial amount of equity indexing in Canada, respectively. The extent of indexing affects the interpretation but not the validity of the tests of the possible explanations of any market effects attributable to index composition changes. Using this logic, Beneish and Gardner (1995) consider information, price pressure, imperfect substitutes, and liquidity explanations for the stock market effects of composition changes in the DJIA, an index seldom mimicked by index funds during the time period they studied.

An examination of TSE300 index revisions allows for tests of market index revision practices that differ from those practices that are used to revise the S\&P500 and DJIA. Two such practices are the annual revision of the TSE300 index and the extended prior notice of index changes during the annual revision of the TSE300. Tests of the annual revisions provide answers about the effect of 'clean' index deletions whose removal is from the index and not the exchange, and whose removal announcement is free of firm-specific confounding information. Such tests are not possible using S\&P500 deletions or TSE300 nonannual deletions, since the abnormal return point estimates of these deletions are affected by survivorship bias since the probability of surviving is related to the criteria used to form the sample of nonannual deletions. ${ }^{7}$ Tests of the longer prior notice period complement the work of Beneish and Whaley (1996) and Lynch and Mendenhall (1997) on the impact of the more recent policy of providing advance notice of required (but less comprehensive) changes to the S\&P500 index. Not only is the advance notice period much longer on the TSE but the annual revision involves a much larger number of simultaneous changes (at least eight simultaneous additions in our sample). ${ }^{8}$ The belief herein

6. The latter type of revision seldom occurs for the S\&P500 index, and occurs much less frequently for the Dow Jones Industrial Average.

7. For discussions of survivorship bias, see, for example, Brown, Goetzmann, and Ross (1995) and Brown and Pope (1995).

8. S\&P typically announces changes to the S\&P500 five business days beforehand. This has varied from 1 to 16 days, and variations occur rarely. The TSE provides about one month 
is that the urgency to rebalance indexed portfolios should be more compelling around annual revisions to the index due to the number of stocks being replaced, and the resultant impact of not rebalancing on the tracking error of an (quasi-)indexer's portfolio.

\section{Competing Explanations for the Price Effects of Index Changes}

According to the price-pressure hypothesis, prices will reverse after the index change. When the heavy index-fund trading subsides around index change dates, stock prices return to their equilibrium values. When deciding when to purchase a stock added to the index, indexers are concerned with the tradeoff between tracking error and payment of a price premium due to temporary price pressure. Under a no-advance notice policy by the index reviser (such as for the S\&P prior to October 1989), indexers buy an added stock after it is added to the index, unless they attempt to anticipate index revisions. Delaying or staggering purchase of an added stock exposes an indexer to tracking error. The indexer expects to pay no premium or a lower premium by pursuing such a purchase policy. Under an advance notice policy by the index reviser, indexers can buy an added stock before, while, or after it is added to the index. This added flexibility allows indexers to better manage the tradeoff between tracking error and temporary price premia caused by temporary price pressure. The expectation herein is that an indexer would concentrate more on tracking error for annual index revisions since they involve many simultaneous changes. However, the expected price pressure and resulting price premium paid by indexers for annual index additions may not be higher than nonannual index additions because of the longer announcement period associated with annual index revisions.

According to the price pressure hypothesis, the measured betas of stocks moving into and out of the index will increase and decrease, respectively, post-index revision (Vijh [1994]). Pruitt and Wei (1989) find that net institutional holdings reported by Value Line increase by less than $2 \%$ for firms that are added to the S\&P500. Although this represents a small proportion of the trading value increase around such

of advance notice of what revisions will be made during its annual revision to the TSE300 index. 
announcements and of the aggregate dollar holdings of institutional investors, Pruitt and Wei argue that this is expected given that other nonindex institutional investors provide liquidity for index institutions.

According to the imperfect substitutes hypothesis, index changes cause permanent price effects. For example, as firms enter the index, purchases by indexers reduce the available share floats of added firms. Given a reduced float, the market clearing price increases permanently if and only if the downward-sloping long-run demand curves of investors are not affected by the longer-run price-insensitive demand behavior of indexers. Harris and Gurel (1986) and Shleifer (1986) argue that their findings of significant positive stock price reactions to the announcements of S\&P500 additions support the price pressure and imperfect substitutes hypotheses, respectively.

According to the liquidity hypothesis, the market-clearing price is affected if index addition or deletion affects the liquidity of the affected stocks. For example, if index addition increases the added stock's liquidity, then the price of the added stock increases upon the announcement of its addition to the index. However, this effect is expected to be temporary according to Amihud and Mendelson's (1986) clientele effect, which postulates that assets allocated in equilibrium to portfolios with longer expected holding periods (such as index portfolios) will have higher spreads (less liquidity). Harris and Gurel (1986) and Edmister et al.(1995) find evidence of a permanent increase in trading volume (a liquidity proxy) following S\&P500 inclusions before October 1989. Similarly, Beneish and Whaley (1996) find evidence of a partially permanent increase in trading volume (number of shares traded) and a temporary reduction in bid/ask spreads following S\&P500 inclusions after October 1989. In contrast, Lynch and Mendenhall (1997) find no evidence of a permanent increase in trading value (dollar value of shares traded) following S\&P500 inclusions after October 1989.

According to the information hypothesis, index addition and deletion announcements have information content or change firm-specific information production or cost. Replacement decisions can only convey information about the future prospects of firms in the unlikely case that the index reviser has and exploits nonpublic information about firms when determining index composition. Inclusion in the index may lead to closer scrutiny of the subject firms by analysts and greater institutional interest. Both of these effects should increase price, since closer analyst scrutiny reduces information risk and cost, and greater 
institutional interest increases potential investor demand. Jain (1987) observes significant stock-price movements for additions and deletions to the S\&P auxiliary indexes not mimicked by indexers, and Dhillon and Johnson (1991) observe significant returns for the options and bonds of firms being added to the S\&P500. While both papers argue that their results support the information (signalling) hypothesis and not the price pressure hypothesis, Dhillon and Johnson (1991) argue that their results are also consistent with the imperfect substitutes hypothesis. However, their results may also be consistent with the hypothesis to be discussed next (i.e., the selection criteria effect hypothesis). Beneish and Gardner (1995) find that the price, trading volume, and quality of available information are unaffected for additions to the DJIA and are decreased by deletions to the DJIA. They conclude that their evidence is consistent with the information cost and liquidity explanations, where investors require premia for bearing exposure to higher trading costs and relatively less information availability.

According to the selection criteria effect hypothesis, the evidence of excess returns for index revisions is not robust. Since S\&P500 and TSE300 replacement selection decisions use historical price information to select stocks for replacement, the historical returns for index additions or deletions are not representative of returns in general. Observations subject to a selection criteria effect generate biased estimates of abnormal returns. Edmister et al.(1994) find that excess returns using parameter estimates based on pre-announcement returns are biased, since index replacements are characterized by rising stock prices during a two-year pre-announcement period (i.e. they tend to be winners over this period).

\section{Sample And Data Description}

An initial sample of 122 TSE300 index changes over the period 19901994 was identified from the TSE Monthly Review. Accounts in the popular financial press attribute these changes to the index's need for more coverage of larger firms and actively traded securities, and due to mergers, reorganizations, failures, and stock reclassifications. ${ }^{9}$ The

9. The former types of index revisions usually occur during the annual revision, and the latter types of index revisions occur during the year as required. Only the latter types of revisions occur for the S\&P500 index. 
initial sample was reduced to a final sample of 112 index additions and 72 index deletions after applying three screens to the initial sample. The first screen removed all units (such as combinations of stocks and debentures) to better focus this study on common share index revisions (removed one index addition and deletion). The second screen removed all share consolidations near the index revision to remove the impact of these confounding events (removed 4 index additions and 7 index deletions). The third screen removed all shares trading for less than two dollars per share (removed 2 index additions and 42 deletions) to remove the impact of low priced shares on price impact. Although this is a customary practice in the literature, unreported results also are discussed for the sample when the third screen is not used. This sample is referred to as the 'final sample plus low-priced changes'. These results are not reported in detail to save valuable journal space.

Trade and quote data are extracted from the TSE Equity History File for the 240 trading days before the index revision announcement date $(A D)$ and the 240 trading days after the index revision effective date (ED) for each index addition/deletion in the final sample. The mean and median number of trading days between the announcement and effective days for our final sample are 16.5 and 19 days, respectively.

The final samples of additions and deletions are also divided based on whether the change was part of an annual revision into annual versus nonannual. This partitioning is designed to examine whether the discretionary changes involved with the annual revisions differ from the nondiscretionary or required changes involved with nonannual revisions to the TSE300 index. The number of firms in the final sample and each sub-sample by year are given in panel A of table 1. Based on panel B of table 1, both the average annual additions and deletions have a lower price and market value of common equity compared to their nonannual counterparts. If the common Canadian small-cap definition of a total market value of common equity of no more than $\$ 250$ million is used, then both the average annual index additions and deletions are small cap firms. Annual index additions and deletions are expected to be smaller in terms of capitalization. The primary criterion for the annual revision of the TSE300 index is to have an index that includes the 300 firms with the largest market capitalization. Like Lynch and Mendenhall (1997) and unlike Beneish and Whaley (1996), the sample of nonannual index deletions is retained for further study. However, as noted by Beneish and Whaley, the findings for this sample are suspect since removed stocks either do not trade or trade for a very short period after deletion, 
TABLE 1. Descriptive Statistics on the Final Sample of TSE300 Index Additions and Deletions

\begin{tabular}{|c|c|c|c|c|}
\hline \multirow[b]{2}{*}{ Year/Statistic } & \multicolumn{2}{|c|}{ Addition } & \multicolumn{2}{|c|}{ Deletion } \\
\hline & Annual & Nonannual & Annual & Nonannual \\
\hline
\end{tabular}

A. Number of Additions and Deletions in the Final Sample

$\begin{array}{lrrrr}90 & 8 & 4 & 4 & 4 \\ 91 & 17 & 7 & 10 & 4 \\ 92 & 18 & 5 & 7 & 5 \\ 93 & 19 & 7 & 11 & 4 \\ 94 & 20 & 7 & 17 & 6 \\ \text { Total } & 82 & 30 & 49 & 23\end{array}$

B. Average Market Value of Common Stock (MVCS) and Per Share Price (P)

$\begin{array}{lccrr}\text { MVCS } & 219 & 510 & 201 & 379 \\ \text { P } & 8.63 & 12.38 & 6 & 14 \\ \text { Number of firms } & 82 & 30 & 49 & 23\end{array}$

Note: The number of additions and deletions remaining in the final sample by year over the period 1990-1994 are reported in panel A. The initial sample consists of 122 pairs of index additions and deletions. Share consolidations remove 4 additions and 7 deletions, units remove 1 addition and 1 deletion, and a market price less than $\$ 2$ per share removes 2 additions and 42 deletions. The average market value of common stock (MVCS) is in millions of dollars and the per-share stock prices $(\mathrm{P})$ for the final sample of additions and deletions are reported in panel $\mathrm{B}$.

or their removal is confounded by firm-specific information. Lynch and Mendenhall (1997) argue that eliminating any firm undergoing merger or spin-off activity at the time of announcement allows them to obtain a 'clean' sample of 15 deletions.

\section{Empirical Results}

In this section of the article, significance is measured at the 5-percent level unless noted otherwise.

\section{A. Trade and Analyst Behavior Around Index Revisions}

This sub-section of the article reports cross-sectional medians of the 
changes in the means for various time periods relative to a benchmark time period for various measures of trade and analyst behavior around revisions to the TSE300 index. The Wilcoxon rank-sum nonparametric test is used to examine the differences in the cross-sectional distributions of each measure of trade and analyst behavior for various time periods relative to a benchmark time period. The medians of the changes in the means are reported because the change over time of each variable for a typical or representative stock going into or coming out of the TSE300 index is of interest. The Wilcoxon rank-sum test is used because the test is not predicated on the assumption of normality and is not affected by outliers in the data set.

The median daily statistics for changes in various measures of trade and analyst behavior for the samples of annual and nonannual index additions and deletions for various event windows from the announcement date $(A D)$ to 60 days after the effective date $(E D)$ relative to the benchmark period are reported in table 2 . The event windows are the announcement window $[A D, \mathrm{AD}+1]$ which covers the announcement and subsequent day, the within-advance-notice window [AD+2, $E D-1]$, which covers the second day after announcement through the first day before the effective day, the effective window $[E D, E D+1]$, which covers the effective and subsequent day, and the post-effective day window $[E D+2, E D+60]$, which covers the second through 60th day after the effective day. The benchmark period covers the 60th up to the first day prior to the announcement date.

The measures of trade behavior include relative volume (number of shares traded for the firm divided by the number of shares traded for the TSE35 index), ${ }^{10}$ percent large trades (i.e. \% $L R G$, or total number of

10. This differs from Beneish and Whaley (1996), who use raw volumes (i.e. volumes unadjusted for general market movements), and Lynch and Mendenhall (1997), who use dollar value of traded volume, and adjust for shares outstanding and general market movements. Lynch and Mendenhall estimate a measure of abnormal volume by differencing the current day's predicted and actual values of transformed volume, given as the log of one plus the dollar value of shares traded for the specific stock divided by the log of one plus the dollar value of shares outstanding for the specific stock. The predicted value uses the estimated intercept and beta coefficients from a simple linear relationship between the transformed volumes of the specific stock against those of the market for the period from 258 to 109 days before the revision announcement dates. The estimated coefficients appear to be biased since the estimations do not appear to reflect the fact that the transformed volumes of the specific stocks are truncated at zero, and those for the market are truncated at some undefined but positive value. Furthermore, Lynch and Mendenhall find various anomalous results such as significant positive abnormal volumes for each of the eight days after the effective date for both index additions and (clean) index deletions. 
TABLE 2. Median Daily Statistics on Changes in Trade and Analyst Behavior Shortly after Index Revision Announcements

\begin{tabular}{|c|c|c|c|c|c|c|}
\hline Measure & (Non) Annual & Benchmark & {$[A D, \mathrm{AD}+1]$} & {$[A D+2, E D-1]$} & {$[E D, E D+1]$} & {$[E D+2, E D+60]$} \\
\hline Relative & Annual & .280 & .068 & .037 & $-.074 * *$ & $-.042 *$ \\
\hline$\%$ of & Annual & .121 & .000 & $.044 * *$ & -.020 & .010 \\
\hline Large Trades & Nonannual & .205 & -.004 & -.005 & .046 & .022 \\
\hline Relative & Annual & .025 & $-.002 * *$ & $-.003 * *$ & $-.003 * *$ & $-.002 * *$ \\
\hline Size & Nonannual & 50 & -5.56 & -13.26 & 11.56 & -.52 \\
\hline \# of & Annual & 1.04 & $.000 * *$ & $.000 * *$ & $.000 * *$ & $000 * *$ \\
\hline Analysts & Nonannual & .000 & NA & NA & NA & $.000 * *$ \\
\hline Predicted & Annual & .028 & .000 & .000 & .000 & $.004 * *$ \\
\hline Growth & Nonannual & .04 & NA & NA & NA & $.002 *$ \\
\hline$\%$ of & Annual & .049 & -.008 & .000 & $-.037 * *$ & .000 \\
\hline Large Trades & Nonannual & .134 & $-.086 * *$ & .134 & $-.1 * *$ & $-.088 * *$ \\
\hline Relative & Annual & .044 & $-.004 *$ & -.003 & -.004 & -.002 \\
\hline Spread & Nonannual & .017 & $.016^{* *}$ & .009 & -.001 & $.014 * *$ \\
\hline Bid & Annual & 23 & -2.97 & 1.77 & -2.72 & -.380 \\
\hline
\end{tabular}




\section{TABLE 2. (Continued)}

\begin{tabular}{llccccc}
\hline Size & Nonannual & 111 & $-51.72 *$ & -9.19 & -20.07 & .000 \\
\# of & Annual & .99 & .000 & .000 & NA & -42.77 \\
Analysts & Nonannual & 2.512 & NA & -.000 & $-.15^{* *}$ \\
Predicted & Annual & -.004 & -.003 & NA & -.003 & NA \\
Growth & Nonannual & .049 & NA & NA & -.001 \\
\hline
\end{tabular}

Note: Median daily statistics on changes in trade and analyst behavior for annual and nonannual additions and deletions for various event windows from the announcement date $(A D)$ to 60 days after the effective date $(E D)$ relative to the benchmark period $(60$ days before until the day before the $A D$ ) are presented in this table. Mean actual values are reported for the benchmark period. Relative (or abnormal) volume is measured as number of shares traded for a security relative to that for the TSE35. \% of large trades is measured as the total number of shares traded for trades of 10,000 shares or more divided by the total number of shares traded. Relative spread is the ask price minus the bid price divided by the midspread. Bid size is in number of round or board lots. \# of analysts is the number of analysts reporting earnings forecasts to $\mathrm{I} / \mathrm{B} / \mathrm{E} / \mathrm{S}$ for the stock. Predicted growth is the five-year earnings growth rate reported by analysts to I/B/E/S. * and ** indicate significance at $10 \%$ and $5 \%$ levels, respectively, for the Wilcoxon rank-sum nonparametric test of the differences between the values for the benchmark $[A D-60$ $A D-1]$ and the other windows. NA refers to not applicable because the $\mathrm{I} / \mathrm{B} / \mathrm{E} / \mathrm{S}$ summary data is updated on a monthly basis and the period between $A D$ and $E D$ is on average only a few days for nonannual index changes. The first numerical value in the first row of 0.280 is the crosssectional mean relative volume during the benchmark period (i.e. the mean daily volume for the annual additions was $28 \%$ of thatfor the TSE35 over the 60 days before until the day before the $A D$ ). The second numerical value in the first row of 0.068 is the median cross-sectional change in the relative volume in the $A D$ period $[A D, A D+1]$ from that for the benchmark period. The third, fourth and fifth numerical values in the first row also are median cross-sectional changes in the relative volume in the period heading their respective column from that for the benchmark period. The remaining rows are interpreted in a similar manner. 
shares traded for trades of 10,000 shares or more divided by the total number of shares traded), relative spread or RS (ask minus bid divided by the mid-spread $)^{11}$, and bid size in number of round or board lots. ${ }^{12}$ The measures of analyst behavior are number of analysts (i.e. the number of analysts reporting EPS forecasts to $\mathrm{I} / \mathrm{B} / \mathrm{E} / \mathrm{S}$ Inc. for a specific month) and predicted growth (i.e. the consensus predictions of five-year growth rates of earnings reported by analysts to $\mathrm{I} / \mathrm{B} / \mathrm{E} / \mathrm{S}$ for a specific month). Given the monthly frequency of these two measures of analyst behavior and the short duration of a few days between the announcement and effective dates for nonannual revisions, these measures are reported for only the post- $A D$ window $[E D+2, E D+60]$ in table 2.

The median percentage of large trades is higher for annual additions only for the within-advance-notice window $[\mathrm{AD}+2, E D-1]$. This suggests that large traders (probably indexers) buy prior to the simultaneous inclusion of numerous stocks into the TSE300 index to better balance the tradeoff between price pressure and tracking error. This is further supported by the finding that relative volume is significantly smaller only for the effective date or $E D$ window [ $E D, E D$ +1 ] for only the annual additions, and that the median relative spreads are significantly lower for the event windows for only annual additions. The median number of analysts following the stocks is significantly higher for both annual and nonannual additions, and the median consensus estimates of five-year growth in earnings per share (EPS) from $\mathrm{I} / \mathrm{B} / \mathrm{E} / \mathrm{S}$ is significantly higher for only annual additions for the post- $E D$ window $[E D+2, E D+60]$. For the two samples of deletions, the median percentages of large trades are significantly smaller for all but the within-advance-notice window for nonannual deletions, and for only the $E D$ window $[E D, E D+1]$ for annual deletions. Thus, large traders appear to avoid making portfolio adjustments on the effective date for simultaneous index deletions and concentrate their portfolio adjustments to the within-advance-notice window when a single deletion occurs. This is supported by the finding that relative volume is significantly lower for the effective date and post-effective date

11. The inferences do not change when absolute (\$) spreads are used.

12. While Beneish and Whaley (1996) examine average trade size, neither Beneish and Whaley (1996) nor Lynch and Mendenhall (1997) examine trading activity by trade size categories (such as large traders). Kryzanowski and Zhang (1996) show that disaggregating data by trade size provides more powerful tests. 
windows for annual deletions and for the announcement date and posteffective date windows for nonannual deletions. The median relative spreads are significantly lower for annual deletions for only the announcement date or $A D$ window and higher for nonannual deletions for the $A D$ and post- $E D$ windows. The median number of analysts following the stocks is significantly lower for nonannual deletions for only the post- $E D$ window $[E D+2, E D+60]$. Interestingly, the actual trade behavior of large traders is consistent with their descriptions of how they trade index additions and deletions. Their descriptions were elicited during personal interviews and are summarized in appendix A.

To examine the permanent nature of the changes identified in the various measures of trade and analyst behavior, such changes now are examined over a longer time span before and after the index revision advance notice windows. The median daily statistics on changes in various measures of trade and analyst behavior for the samples of annual and nonannual index additions and deletions are reported in table 3 . The changes are calculated for each measure for quarters -3 to -1 before the announcement date and from quarters +1 to +4 after the effective date relative to the benchmark quarter -4 . Each quarter consists of 60 trading days. These findings strongly suggest that index revisions, at least to the TSE300 index, have no permanent effects on measures of trade (such as liquidity) and analyst behavior. Few of the median changes are significant for index additions and none of the changes is significant for analyst behavior for index deletions. Nonannual index deletions exhibit a significant decrease in median percentages of large trades and increase in median relative spreads during quarter +1 relative to benchmark quarter -4 . For index additions, no significant changes are identified in the median percentages of large trades or relative spreads. The only significant changes are the decrease in bid size for quarter +4 (annual only) and the decrease in relative volume for quarter +1 (nonannual only). Significant median increases occur for analyst following for all quarters and for predicted growth for only the annual additions. Since our inferences based on market-adjusted volumes differ markedly from those of Beneish and Whaley (1996), the volume changes now are examined using the nonmarket-adjusted measure used by Beneish and Whaley. Based on unreported results, significant and positive nonmarketadjusted volume changes relative to the pre- $A D$ benchmark volumes occur for the annual index additions and deletions for the withinadvance notice period [AD+2, ED-1]. The nonmarket-adjusted volume 
TABLE 3. Median Daily Statistics for Longer-term Trade and Analyst Behavior around Index Revision Advance Notice Periods

\begin{tabular}{|c|c|c|c|c|c|c|c|c|c|}
\hline Measure & (Non) Annual & Benchmark & -3 & -2 & -1 & 1 & 2 & 3 & 4 \\
\hline \multicolumn{10}{|c|}{ A. Median daily statistics for the 82 annual and 30 nonannual additions } \\
\hline Relative & Annual & .190 & .039 & .022 & -.009 & -.005 & $.047 *$ & -.01 & .016 \\
\hline Volume & Nonannual & .540 & -.022 & -.064 & -.063 & $-.288 * *$ & -.224 & -.154 & -.178 \\
\hline$\%$ of & Annual & .084 & .001 & .002 & .014 & .013 & .008 & .02 & .011 \\
\hline Large Trades & Nonannual & .147 & -.023 & -.015 & .001 & .033 & .012 & .04 & .007 \\
\hline Relative & Annual & .026 & $-.003 *$ & $-.002^{*}$ & .001 & -.001 & .000 & .000 & .001 \\
\hline Spread & Nonannual & .024 & -.001 & -.001 & .000 & -.001 & .000 & -.001 & -.002 \\
\hline Bid & Annual & 29 & 2.68 & -2.35 & -2.8 & -1.14 & -.46 & $-5.16^{*}$ & $-7.58 * *$ \\
\hline Size & Nonannual & 56 & -5.92 & -3.52 & -6 & -.64 & $-10.92^{*}$ & $-11.09 *$ & -16.52 \\
\hline$\#$ of & Annual & .000 & $.000 * *$ & $.000 * *$ & $.000 * *$ & $.000 * *$ & $.23 * *$ & $1.12 * *$ & $1.13 * *$ \\
\hline Analysts & Nonannual & .000 & $.000 * *$ & $.000 * *$ & $.000 * *$ & $.000 * *$ & $.13 * *$ & $1.56 * *$ & $2.0 * *$ \\
\hline Predicted & Annual & .018 & $.004 * *$ & $.005^{* *}$ & $.007 * *$ & $.01 * *$ & $.015^{* *}$ & $.012 * *$ & $.008 * *$ \\
\hline Growth & Nonannual & .012 & .001 & .004 & $.005^{*}$ & .005 & $.011^{*}$ & $.017 *$ & $.02 * *$ \\
\hline \multicolumn{10}{|c|}{ B. Median daily statistics for the 49 annual and 23 non annual deletions } \\
\hline Relative & Annual & .06 & .006 & -.004 & .009 & -.004 & .002 & .002 & .01 \\
\hline Volume & Nonannual & .16 & $-.072 * *$ & -.03 & .203 & $-.334 *$ & -.161 & -.205 & -.206 \\
\hline$\%$ of & Annual & .035 & -.008 & $-.008^{*}$ & .000 & -.001 & -.002 & -.001 & .000 \\
\hline Large Trades & Nonannual & .086 & -.019 & -.027 & .039 & $-.063 * *$ & .035 & -.001 & -.002 \\
\hline Relative & Annual & .033 & .003 & -.001 & .002 & .000 & .002 & .001 & .001 \\
\hline Spread & Nonannual & .019 & .000 & .001 & -.003 & $-.019 * *$ & .022 & -.008 & .003 \\
\hline Bid & Annual & 20 & -.18 & .990 & 3.870 & $-2.57 *$ & 1.18 & -.34 & .44 \\
\hline
\end{tabular}


TABLE 3. (Continued)

\begin{tabular}{llccrrrrrrr}
\hline Size & Nonannual & 22 & .12 & 2.09 & $63.51^{* *}$ & 20.61 & 1.61 & .54 & 4.98 \\
\# of & Annual & 1.46 & .000 & .000 & .000 & .000 & .000 & .000 & .000 \\
Analysts & Nonannual & 3 & .000 & .000 & .000 & .000 & .000 & .5 & .2 \\
Predicted & Annual & .014 & .001 & -.004 & -.013 & -.006 & .006 & .002 & .002 \\
Growth & Nonannual & .044 & .000 & .006 & .003 & .006 & .000 & -.039 & -.029
\end{tabular}

Note: Median daily statistics on changes in trade and analyst behavior for annual and nonannual additions and deletions for quarters -3 to -1 before the announcement date and from quarters +1 to +4 after the effective date, relative to the benchmark (quarter -4$)$, are reported in this table. Mean actual values are reported for the benchmark period. Each quarter consists of 60 trading days. Relative (or abnormal) volume is measured as number of shares traded for a security relative to that for the TSE35. \% of large trades is measured as the total number of shares traded for trades of 10,000 shares or more divided by the total number of shares traded. Relative spread is the ask price minus the bid price divided by the midspread. Bid size is in number of round or board lots. \# of analysts is the number of analysts reporting earnings forecasts to $\mathrm{I} / \mathrm{B} / \mathrm{E} / \mathrm{S}$ for the stock. Predicted growth is the five-year growth in EPS predictions reported by analysts to I/B/E/S. * and ** indicate significance at $10 \%$ and $5 \%$ levels, respectively, for the Wilcoxon rank-sum test of the differences in values between the benchmark (quarter -4) and other quarters. As of quarter 4, 80 annual additions, 25 nonannual additions, 45 annual deletions, and 2 nonannual deletions remained in their respective samples. The remainder had been delisted. The first numerical value in the first row of 0.190 is the cross-sectional mean relative volume during the benchmark period (i.e. the mean daily volume for the annual additions was $19 \%$ of that for the TSE35 over the fourth quarter before the $A D$ ). The second numerical value in the first row of 0.039 is the median cross-sectional change in the relative volume for the third quarter before the $A D$ from that for the benchmark quarter. The third through eighth numerical values in the first row also are median cross-sectional changes in the relative volume for the quarters heading their respective columns from that for the benchmark period. The remaining rows are interpreted in a similar manner. 
changes for the $A D$ window relative to the pre- $A D$ benchmark volumes are positive but not significant for both annual index additions and deletions. Thus, the findings of this article are more consistent with those of Beneish and Whaley if their nonmarket-adjusted volume measure is used.

\section{B. Price Effects of Index Revisions}

To facilitate comparison of the price effect findings with those of Beneish and Whaley (1996) and Lynch and Mendenhall (1997), the cross-sectional mean market-adjusted cumulative abnormal returns $(C A R)$ are calculated first for nine event windows drawn from the period starting 60 days prior through 240 days after the announcement date. $^{13}$ Based on the results summarized in panel A of table 4, significant positive mean $C A R$ are found for the $A D$ window $[A D$, $\mathrm{AD}+1$ ] for additions only, and significant positive mean $C A R$ are found for the within-advance notice window $[\mathrm{AD}+2, E D-1]$ for only annual index additions. The mean $C A R$ of $1.7 \%$ and $2.5 \%$ for annual and nonannual additions, respectively, for the $A D$ window appear economically significant, and are somewhat smaller than those found for S\&P500 revisions. Based on the significant mean CAR for the pre$A D$ window $[A D-60, A D-1]$ for additions, it is evident that additions are drawn from stocks (so-called winners) that have performed abnormally well relative to the market prior to their selection for index inclusion. This is further supported by the mean market-adjusted $C A R$ which are significantly positive for quarters $-4,-3$ and -1 for annual index additions and for quarters $-4,-3,-2$ and -1 for nonannual index additions. The market-adjusted $C A R$ are significantly negative for quarters +3 and +4 for annual index additions only. The mean marketadjusted $C A R$ are significantly negative for quarters $-4,-3$ and -2 for annual index deletions and for quarter-4 for nonannual index deletions. Thus, based on the quarterly market-adjusted $C A R$, deletions appear to be drawn from stocks (so-called losers) that have performed abnormally poorly relative to the market prior to their removal from the index. These findings suggest that inferences based on the initial (marketadjusted) $C A R$ results may not be robust because of a selection criteria effect that may generate biased estimates of cumulative abnormal

13. Overnight returns are not used in this article because Chung and Kryzanowski (1997a) find that significant AR occur after the index revision announcements but not overnight. This differs from the finding of Beneish and Whaley (1996). 
returns $(C A R)$. Based on results for the final sample plus low-priced changes, which are not reported herein, more of the market-adjusted $C A R$ are significant for the additions and deletions. For this sample, the market-adjusted $C A R$ also are negative for the annual deletions for the $A D$ window $[A D, A D+1]$ and the pre- $A D$ window $[A D-60, A D-1]$. The market-adjusted $C A R$ now are significantly positive (negative) for all pre- $A D$ quarters for index additions (deletions), with the exceptions of quarters -2 for annual deletions and -1 for nonannual deletions.

\section{Robustness Tests of Price Effects Associated with Index Revisions}

The first test of the robustness of the abnormal returns for the $A D$ window $[A D, \mathrm{AD}+1]$ uses the Boehmer, Musumeci, and Poulsen (1991) adjustment to the cross-sectional technique for assessing the significance of event date $A R$. This adjustment accounts for eventinduced variance. Specifically, a t-test based on a cross-section of each stock's standardized abnormal returns or SAR for the event date is used instead of the unstandardized $A R$. The $S A R$ for stock $i$ is given by

$$
S A R_{i}=\frac{A R_{i, E}}{E S T \quad S_{i} \sqrt{1+\frac{1}{T_{i}}+\frac{\left(R_{m, E}-\bar{R}_{m}\right)^{2}}{\sum_{i=1}^{T_{i}}\left(R_{m, t}-R_{m}\right)^{2}}}}
$$

where $A R_{i, E}$ is stock $i$ 's $A R$ for the event date ' $E$ ', $T_{i}$ is the number of days in stock $i$ 's estimation period, $R_{m, t}$ is the market return for day $t, R_{m, E}$ is the market return for the event date, $\bar{R}_{m}$ is the average market return during the estimation period, and $E s t s_{i}$ is stock $i$ 's estimated standard deviation of $A R$ for the estimation period. Since a two-day event date is used herein, two-day returns are used for the stock and the market in the above test.

The $S A R$ are calculated using equation 1 and the $A R$ from a simple market model. ${ }^{14}$ The inferences change somewhat based on this new set

14. The traditional two-step procedure and two-day returns are used for this purpose. First, the daily returns for each index change and for the corresponding daily returns for the market are changed into cumulative two-day returns. As a result, the interval $[A D-240, A D-1]$ became $[A D-120, A D-1]$, and the $A D$ window $[A D, A D+1]$ became $[A D]$. Next, a simple market model is run using the returns for $[A D-120, A D-1]$ to estimate the market model alpha and beta for each index addition and deletion. Finally, each alpha and beta estimate is used to compute the two-day cumulative abnormal return or $C A R$ for each index addition and deletion for the $A D$ window $[A D]$. 
TABLE 4. Mean Market-adjusted Cumulative Abnormal Returns

\begin{tabular}{|c|c|c|c|c|c|c|c|c|c|c|}
\hline $\begin{array}{l}\text { Add } \\
\text { /Del }\end{array}$ & $\begin{array}{l}\text { (Non) } \\
\text { Annnual }\end{array}$ & $\begin{array}{l}{[A D-60} \\
A D-1]\end{array}$ & $\begin{array}{l}{[A D,} \\
A D+1]\end{array}$ & $\begin{array}{l}{[A D+2,} \\
E D-1]\end{array}$ & $\begin{array}{l}{[E D+2,} \\
E D+1]\end{array}$ & $\begin{array}{l}{[E D+2,} \\
E D+10]\end{array}$ & $\begin{array}{l}{[A D,} \\
A D+30]\end{array}$ & $\begin{array}{l}{[A D,} \\
A D+60]\end{array}$ & $\begin{array}{l}{[A D,} \\
A D+120]\end{array}$ & $\begin{array}{l}{[A D,} \\
A D+240]\end{array}$ \\
\hline
\end{tabular}

A. Mean market-adjusted cumulative abnormal returns for various event windows from $A D-60$ (the announcement date minus 60 trading days) through $A D+240$ (the announcement date plus 240 trading days). $E D$ refers to the effective date. $N$ refers to the sample size.

\begin{tabular}{rlccccccrrrr}
\multirow{3}{*}{ Add } & Annual & $.065^{* *}$ & $.017^{* *}$ & $.041^{* *}$ & .006 & .024 & $.049^{* *}$ & $.073^{* *}$ & .053 & -.012 \\
& $(N=82)$ & $(1.96)$ & $(3.36)$ & $(2.53)$ & $(1.37)$ & $(1.02)$ & $(2.67)$ & $(2.24)$ & $(1.61)$ & $(-1.1)$ \\
& Nonannual & $.105^{* *}$ & $.025^{* *}$ & .006 & .014 & -.012 & -.026 & -.005 & .013 & .02 \\
& $(N=30)$ & $(2.03)$ & $(3.07)$ & $(.45)$ & $(1.89)$ & $(-1.03)$ & $(-1.1)$ & $(-.14)$ & $(.49)$ & $(.63)$ \\
Deletion & Annual & -.044 & -.013 & .002 & .008 & .057 & .055 & .064 & .095 & .142 \\
& $(N=49)$ & $(-.92)$ & $(-1.21)$ & $(.43)$ & $(.38)$ & $(1.39)$ & $(1.69)$ & $(.24)$ & $(1.7)$ & $(1.79)$ \\
& Nonannual & .033 & .029 & .285 & -.032 & .166 & .056 & .185 & .266 & .208 \\
& $(N=23)$ & $(1.78)$ & $(.84)$ & $(.98)$ & $(-1.62)$ & $(1.13)$ & $(.46)$ & $(1.44)$ & $(1.53)$ & $(1.04)$ \\
\hline
\end{tabular}




\section{TABLE 4. (Continued)}

B. Mean market-adjusted cumulative abnormal returns for quarters -4 to -1 before the announcement date, and from quarter +1 to +4 after the effective date. Each quarter consists of 60 trading days.

\begin{tabular}{|c|c|c|c|c|c|c|c|c|c|}
\hline & & & & & & & 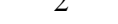 & & I \\
\hline \multirow[t]{4}{*}{ Add } & \multirow[t]{2}{*}{ Annual } & $.212 * *$ & $.094 * *$ & .026 & $.065^{* *}$ & .005 & -.02 & $-.057 * *$ & $-.055^{* *}$ \\
\hline & & $(3.92)$ & (2.69) & $(.82)$ & (1.96) & $(.25)$ & $(-1.01)$ & $-2.53)$ & $(-2.17)$ \\
\hline & \multirow[t]{2}{*}{ Nonannual } & $-.102 * *$ & $.185 * *$ & $.173 * *$ & $.105 * *$ & -.009 & .008 & .028 & -.002 \\
\hline & & $(1.98)$ & $(2.01)$ & $(2.51)$ & $(2.03)$ & $(-.26)$ & $(.3)$ & $(.71)$ & $(-.06)$ \\
\hline \multirow[t]{4}{*}{ Deletion } & \multirow[t]{2}{*}{ Annual } & $-.101 * *$ & $-.139 * *$ & $-.106 * *$ & -.044 & .019 & -.022 & .024 & -.007 \\
\hline & & $(-3.79)$ & $(-6.91)$ & $(-3.89)$ & $(-.92)$ & $(.5)$ & $(-.5)$ & $(.71)$ & $(-.18)$ \\
\hline & \multirow[t]{2}{*}{ Noannual } & $-.085 * *$ & -.088 & -.092 & .033 & .061 & .269 & -.109 & -.047 \\
\hline & & $(-2.01)$ & $(-1.92)$ & $(-1.56)$ & (1.78) & (.97) & (1.56) & $(-.66)$ & $(-.25)$ \\
\hline
\end{tabular}

Note: Mean market-adjusted cumulative abnormal returns for the annual and nonannual samples of index additions (Add) and index deletions are reported in this table. ** indicates significance at the $5 \%$ level for the t-test. T-values are reported in the parentheses. 
of $t$-tests for only the final sample. The $A D$ window price effects are now negative and significant for annual index deletions. ${ }^{15}$ These new results are robust to whether raw (actual) returns or excess returns (i.e. actual returns minus the risk-free returns) are used in the tests.

The abnormal returns around TSE300 index revisions obtained from four modified market models now are tested. These abnormal return estimates should be more robust than those obtained in the previous subsection from only market-adjusting the event window returns. The first modified market model captures the selection criteria effect (discussed earlier) and is specified as: ${ }^{16}$

$$
\begin{gathered}
R_{i, t}-R_{f, t}=\alpha_{i, 1}\left(1-D_{1}\right)+\alpha_{i, 2} D_{1} \\
+\beta_{i, 1}\left(R_{m, t}-R_{f, t}\right)+l_{i} D_{2}+\varepsilon_{i, t}
\end{gathered}
$$

where $R_{i, t}$ is the return on index addition or deletion $i$ at time $t, R_{f, t}$ is the risk-free rate at time $t$ as proxied by the call loan rate charged by brokers to their clients, $D_{1}$ is a dummy variable, with ones on and after the announcement date and zeros otherwise, $\alpha_{i, t}$ is the Jensen performance index (i.e., the abnormal performance for index addition or deletion $i$ in the pre- $A D$ window when $k=1$, and in the post- $A D$ period when $k=2$ ), $\beta_{i, 1}$ is the sensitivity of index addition or deletion $i$ to the market over the whole time period, $t_{i}$ is the average daily abnormal return for the two-day announcement window $[A D, \mathrm{AD}+1]$, $D_{2}$ is a dummy variable, with ones on the two-day announcement window and zeros otherwise, $\varepsilon_{i, t}$ is the error term of the relationship at time $t$ for index addition or deletion $i$, which is assumed to be distributed normally with mean equal to zero, constant variance, and zero correlation between the error terms both across and over time.

As noted in the introduction, Vijh (1994), among others, shows that the betas based on daily returns of stocks added to or deleted from the

15. For the final sample, the mean two-day $S A R$ and their respective $t$-values are 1.015 $(2.80 * *)$ for nonannual index additions, $0.357(2.81 * *)$ for annual index additions, 0.067 (0.335) for nonannual index deletions, and - 0.331 (- $\left.2.035^{* *}\right)$ for annual index deletions. For the final sample plus low-priced stocks, the mean two-day $S A R$ and their respective $t$-values are $0.988\left(2.93^{* *}\right)$ for nonannual index additions, 0.361 (2.97**) for annual index additions, $0.000(0.001)$ for nonannual index deletions, and $-0.301\left(-2.14^{* *}\right)$ for annual index deletions.

16. This is a modification of the market model used by Kryzanowski and Zhang (1992), among others, to study continuation and reversal behavior of stock prices. Adding an announcement-date dummy modifies the formulation of Kryzanowski and Zhang. 
S\&P500 change. Kryzanowski and To (1982) prove that parameters estimates for traditional single- and two-factor models change depending on whether the studied stock is part of the market proxy. Thus, the second model is obtained by adding a market sensitivity shift term to equation 2 to get:

$$
\begin{gathered}
R_{i, t}-R_{f, t}=\alpha_{i, 1}\left(1-D_{1}\right)+a_{i, 2} D_{1}+\beta_{i, 1}\left(R_{m, t}-R_{f, t}\right) \\
+\beta_{i, 2}\left(R_{m, t}-R_{f, t}\right) D_{1}+l_{i} D_{2}+\varepsilon_{i, t}
\end{gathered}
$$

where $\beta_{i, 2}$ is the change in the market sensitivity or beta of index addition or deletion $i$ after the $A D$ window, and all the other terms are as defined earlier.

The third modified market model is obtained by adding terms to capture liquidity changes and large trade activity to equation 2 . The motivation for adding the liquidity factor is two-fold. First, the liquidity hypothesis argues that the market-clearing price is affected if index additions or deletions affect the liquidity of these stocks. Second, Amihud and Mendelson (1986) and Brennan and Subrahmanyam(1996) find a significant relationship between required rates of return and measures of illiquidity (such as the bid-ask spread). The large trade activity factor is added because the primary motivating force behind the price-pressure hypothesis is the price impact of heavy index-fund trading around index change dates. The third model is specified as:

$$
\begin{gathered}
R_{i, t}-R_{f, t}=\alpha_{i, 1}\left(1-D_{1}\right)+\alpha_{i, 2} D_{1}+\beta_{i, 1}\left(R_{m, t}-R_{f, t}\right) \\
+\beta_{i, 3} R S_{i}+\beta_{i, 4} L R G_{i}+\iota_{i} D_{2}+\varepsilon_{i, t}
\end{gathered}
$$

where $R S_{i}$ is the relative spread, calculated as the (ask price - bid price) $\div$ midspread, $L R G$ is percent (\%) of large trades, calculated as the total number of shares traded for trades of 10,000 shares or more divided by the total number of shares traded, $\beta_{i 3}$ and $\beta_{i 4}$ are the sensitivities of index addition or deletion $i$ to changes in the relative spread and percent (\%) of large trades, respectively, and all other terms are as defined previously.

The fourth model is the first model estimated using a $G L S$ when the $\varepsilon_{i, t}$ follow an autoregressive $A R-1$ process. This is an alternate way of capturing the impact of the selection criteria effect caused by the fact 
that index additions and (annual) deletions tend to be drawn from stocks that have done well and poorly, respectively.

Both excess and raw returns are used in all four models. However, excess returns are preferred because the resulting $\alpha_{i, k}$ coefficients are expected to be equal to zero if no abnormal return performance has occurred. Thus, the use of excess returns facilitates statistical testing of the significance of the estimated alpha coefficients.

A Scholes-Williams (1977) adjustment of the betas (SW betas) for thin trading is used for all four modified market models. This beta adjustment is accomplished by including not only the contemporaneous market return in each model but also the lagged and lead market return. The SW beta estimate, SW $\beta_{i 1}^{*}$, is then calculated, for example, for the first modified market model as:

$$
S W \beta_{i, 1}^{*}=\frac{\left(\beta_{i, 1,-1}^{*}+\beta_{i, 1,0}^{*}+\beta_{i, 1,1}^{*}\right)}{(1+2 \rho)}
$$

where $\beta_{i, 1, k}^{*}$ is the estimated beta for stock $i$ based on the lagged, contemporaneous, or lead market return, if $k=-1,0$ or 1, respectively, and $\rho$ is the first-order autocorrelation coefficient for the market return over stock $i$ 's estimation period.

The null hypothesis $\left(\alpha_{i, 1}=0\right)$, when using excess returns, implies the absence of a selection criteria effect. A significant $\alpha_{i, 1}>0$ for index additions and $\alpha_{i, 1}<0$ for index deletions, when using excess returns, indicates that additions and deletions are drawn from historical winners and losers, respectively. Significant $\alpha_{i, 1}$ and $\alpha_{i, 2}$ of the same (different) sign for index additions or deletions, when using excess returns, indicates price continuation (reversal) behavior. The null hypothesis $\left(\alpha_{i, 2}=0\right)$, when using excess returns, implies the absence of any permanent liquidity and/or price effects. Unlike Lynch and Mendenhall (1997) who use windows of [AD+1,ED +7] and [AD+1, ED +5] for index additions and deletions, respectively, to test the imperfect substitutes hypothesis, up to 240 trading days post- $A D$ are used herein. As in Vijh (1994), p.221, the belief herein is that any liquidity-related and temporary price effects must revert over a sufficiently long time period. This null hypothesis is tested using estimates of $\alpha_{i, 2}$ which first exclude the announcement window observations to facilitate comparison with Lynch and Mendenhall, and then include the announcement window observations to provide a more robust test of the 
permanent price effects of index additions and deletions.

A regression corresponding to each model for each index addition and deletion is first run using data on the variables of interest for the 240 days before through the 240 days after the announcement date of index revision. Then summary statistics are calculated based on the mean values of the cross-sectional estimates for the sample of annual and nonannual index additions and deletions. These empirical findings using excess returns are presented in table 5. Based on unreported results, the same inferences are obtained using raw returns.

The mean alpha estimates are summarized in table 5 for the four more robust market models. These estimates only support a winnernormal behavior for annual index additions. ${ }^{17}$ Most of the other pre- $A D$ and post $-A D$ mean alpha estimates are not significant for the samples of nonannual index additions and annual and nonannual index deletions.

While all of the mean Scholes-Williams-adjusted betas are less than one, they are not significant for the nonannual index deletions. While all of the mean Scholes-Williams-adjusted market beta shift estimates are of the correct sign, none of them is significant. ${ }^{18}$ The mean coefficient estimates for the relative spread variable is negative and significant ${ }^{19}$ for annual index additions and deletions, and none of the mean coefficient estimates for the large trade variable are significant. Thus, the relative spread variable helps to explain the excess returns of index additions and deletions.

Most of the means of the more robust estimates of the average abnormal returns for the announcement window are significant for all but the sample of nonannual index deletions. However, the economic significance of the $A R \mathrm{~s}$ is somewhat marginal (less than 60 basis points) for all but the nonannual additions. ${ }^{20}$

To test if any abnormal returns associated with index changes are permanent, each of the four modified market models are reestimated without the $A D$ window dummy variable. The mean estimates of post-

17. The support also includes nonannual index additions for the final sample plus lowpriced stocks.

18. All of the mean Scholes-Williams-adjusted beta estimates are significant for the final sample plus low-priced stocks

19. The mean coefficient estimate is positive and significant for annual additions for the final sample plus low-priced stocks.

20. Similar results are obtained from the final sample plus low-priced stocks. 
TABLE 5. Mean Statistics on Coefficient Estimates for Regressions of Excess Returns against Various Independent Variables

\begin{tabular}{|c|c|c|c|c|c|c|c|c|}
\hline \multirow[b]{2}{*}{ Coefficients } & \multicolumn{4}{|c|}{ Nonannual } & \multicolumn{4}{|c|}{ Annual } \\
\hline & 1 & 2 & 3 & 4 & 5 & 6 & 7 & 8 \\
\hline \multicolumn{9}{|c|}{ A. For the samples of nonannual and annual index additions } \\
\hline$\alpha_{1}$ & $\begin{aligned} .001 \\
(1.76)\end{aligned}$ & $\begin{array}{l}.002 * * \\
(2.09)\end{array}$ & $\begin{array}{r}.002 \\
(1.48)\end{array}$ & $\begin{array}{r}.001 \\
(1.76)\end{array}$ & $\begin{array}{r}.001 \\
(2.55)\end{array}$ & $\begin{array}{l}.001 * * \\
(2.59)\end{array}$ & $\begin{array}{l}.003^{* *} \\
(3.48)\end{array}$ & ${ }_{(2.53)}^{.001 * *}$ \\
\hline$\alpha_{2}$ & .000 & .000 & .001 & .000 & -.000 & $\begin{array}{l}(2.09) \\
-.000 \\
(-63)\end{array}$ & (3.48) & $\begin{array}{l}(2.53) \\
-.000 \\
(-55)\end{array}$ \\
\hline$f_{1}$ & $.551 * *$ & $.409 * *$ & $.552^{* * *}$ & $.553 * *$ & $.601 * *$ & $.489 * *$ & $.587 * *$ & $.606 * *$ \\
\hline$f_{2}$ & & $\begin{array}{l}(2.73) \\
.162 \\
(1.06)\end{array}$ & & & & $\begin{array}{l}(5.01) \\
.121 \\
(1.21)\end{array}$ & & \\
\hline$f_{3}$ & & & $\begin{array}{l}-.017 \\
(-.16)\end{array}$ & & & & $(-.103 * *$ & \\
\hline$f_{4}$ & & & $\begin{array}{l}.000 \\
(.02)\end{array}$ & & & & $\begin{array}{c}.002 \\
(1.59)\end{array}$ & \\
\hline i & $\begin{array}{l}.033 * * \\
(2.16)\end{array}$ & $\begin{array}{l}.033 * * \\
(2.16)\end{array}$ & $\begin{array}{l}.033^{* * *} \\
(2.17)\end{array}$ & $\begin{array}{l}.033^{* *} \\
(2.18)\end{array}$ & $(4)^{.006^{* *}}$ & $\begin{array}{l}.006^{*} \\
(4.11)\end{array}$ & $\begin{array}{l}.006 * * \\
(4.04)\end{array}$ & $\begin{array}{l}.006^{* *} \\
(3.95)\end{array}$ \\
\hline$R_{*}^{2}$ & $\begin{array}{r}.001 \\
(1.77)\end{array}$ & $\begin{array}{r}.001 \\
(1.73)\end{array}$ & $\begin{array}{r}.001 \\
(1.05)\end{array}$ & $\begin{array}{r}.001 \\
(1.78)\end{array}$ & $\begin{array}{l}-.000 \\
(-.12)\end{array}$ & $\begin{array}{l}-.000 \\
(-.20)\end{array}$ & $\begin{array}{c}.002 \\
(2.37)\end{array}$ & $\begin{array}{l}-.000 \\
(-.13)\end{array}$ \\
\hline
\end{tabular}




\section{TABLE 5. (Continued)}

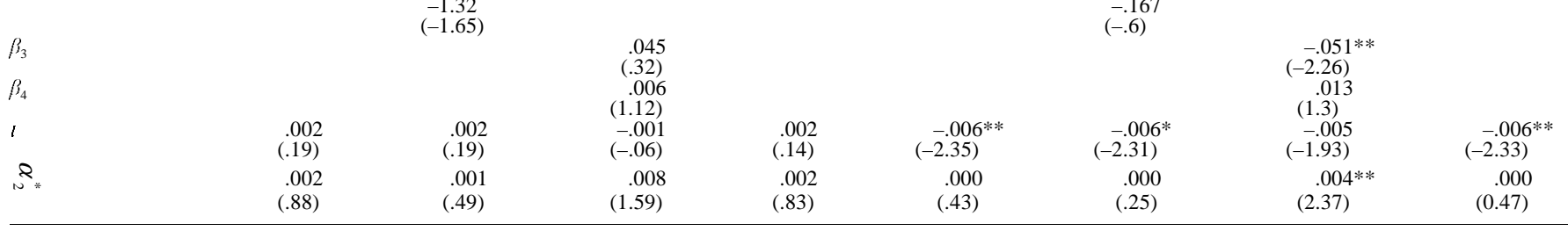

Note: Mean statistics for the coefficient estimates from regressing excess returns on the index additions and deletions against various independent variables using data from 240 days before through 240 days after the announcement date $(A D)$ are presented in this table. $\alpha_{1}$ and $a_{2}$ are the Jensen measures of excess return for the periods before and after the announcement date. $\alpha_{2}$ is the Jensen measure of excess return from the announcement date onwards (i.e. with the $A D$ window dummy removed). $\beta_{1}$ is the sensitivity of the excess return on additions or deletions to the excess returns on the market over the whole period. $\beta_{2}$ is the change in the sensitivity of the excess returns on additions or deletions to the excess returns on the market after the $A D$ window. These are Scholes-Williams-adjusted betas [see equation (5) in the text]. $\beta_{3}$ and $\beta_{4}$ are the sensitivities of the excess returns of additions or deletions to the changes in the relative spread and \% of large trades, respectively. 1 is the average daily abnormal return over the two-day announcement window $[A D, A D+1]$. Four regressions are run for each annual and nonannual addition and deletion. The first regression estimates the first modified market model that captures the selection criteria effect by including a Jensen alpha before and after the $A D$ window [see equation (2) in the text]. The second regression estimates the second modified market model that is obtained by adding a market sensitivity shift term to the first model [see equation (3) in the text]. The third regression estimates the third modified market model which is obtained by adding terms to capture liquidity changes and changes in large trade activity to the first model [see equation (4) in the text]. The fourth regression estimates a version of the first model using a GLS when the error terms of the first model follow an autoregressive $A R-1$ process. After the four regressions are run for each addition and deletion, summary statistics are computed based on cross-sectional estimates for the samples of annual and nonannual index additions and deletions. $* *$ indicates significance at the $5 \%$ level. $T$-values are reported in the parenthese 
$A D$ alphas $\alpha_{2, *}$ are significant (and positive) only for annual index additions and deletions for the third modified market model.

Thus, the empirical findings reported herein support the pricepressure hypothesis and not the imperfect substitutes hypothesis, although no statistically significant evidence is found to support the price pressure hypothesis prediction that measured betas of index and nonindexed stocks increase and decrease, respectively, post-index revision. Index revision announcements cause significant abnormal returns with the expected sign over the announcement window (positive for additions and negative for annual deletions) but do not appear to cause permanent price effects. Any abnormal returns associated with the announcement window essentially vanish in the post- $A D$ period.

\section{Determinants of Announcement Window CAR}

This sub-section of the article examines the importance of ten potential determinants of the announcement window $[A D, \mathrm{AD}+1] C A R$. This is done by first conducting three cross-sectional regressions using the $C A R$ based on market-adjusted returns as the dependent variable. These three regressions then are repeated using the $C A R$ based on the first modified market model abnormal returns as the dependent variable and then the $S A R$ values. ${ }^{21}$ In all the regressions, the White (1980) adjustment is used to correct for heteroscedasticity. The independent variables used in one or more of these regressions are a dummy variable, $A N N$, for whether the stock was involved in an annual or nonannual index revision (1 and 0 , respectively); a dummy variable, $A D D$, for whether the stock was an addition or a deletion ( 1 and 0 , respectively); the natural $\log$ of the market value of common stock or MVCS (as of day $A D-1$ ); the number of analysts following the stock as reported by I/B/E/S or \#ANAL (as of day $A D-1$ ); the contemporaneous cumulative trading volume of the stock relative to that for the market or $R V_{0}$; the Cumulative Abnormal Return for the stock over the subsequent 240 trading days or CAR240 (i.e. over the period [AD+2, AD+241]); the change in the percentage of large trades or $\Delta \% L R G$; the change in the relative spread or $\Delta R S$; the change in the number of analysts following the stock or $\triangle \% A N A L$; and the change in the consensus expected five-year growth in EPS of analysts reporting to $\mathrm{I} / \mathrm{B} / \mathrm{E} / \mathrm{S}$ or $\Delta E s t g$. The last four independent variables (namely, $\Delta \% L R G, \triangle R S, \Delta \% A N A L$ and $\triangle E s t \mathrm{~g}$ ) are equal to

21. Similar results are obtained from the CAR of the other three modified market models. 
their changes calculated using the 60-day period starting two-days after the effective date (i.e. $[E D+2, E D+61]$ ) relative to the 60 -day period ending the day before the announcement date (i.e. [AD-60, $A D-1])$.These cross-sectional regressions allow for a further evaluation of the potential competing explanations simultaneously. Regressors that allow for tests of price pressure include $R V_{0}$ and $\triangle \% L R G$, of imperfect substitutes include $C A R 240$, of liquidity include $\mathrm{DRS}$, and of information include \#ANAL, $\triangle \% A N A L$ and $\triangle E s t \mathrm{~g} .{ }^{22}$ The regression results are reported in table 6 . The announcement window $C A R$ or $S A R$ generally are significantly and positively related to the index add dummy $A D D$ ( 1 for addition and 0 for deletion). The announcement window $C A R$ (not $S A R$ ) is significantly and positively related to expectations about firm prospects $\Delta E s t y$. This provides weak support for the information hypothesis.

\section{Concluding Remarks}

This article examined the market effects of index revisions for the TSE300 index over the five-year period, 1990-1994. Revisions to this index are of interest because they allow for tests of index revision practices that differ from those used for S\&P500 and DJIA revisions. Two such practices are the annual index revisions and the extended prior notice of the affected stocks for the annual revision of the TSE300 index. Tests of the former provide answers about the effect of 'clean' index deletions whose removal is from the index and not the exchange and whose removal announcement is free of firm-specific confounding information disclosure. Tests of the latter allow for the assessment of the impact of providing advance notice of changes to an index when the advance notice period is relatively long and each revision involves numerous simultaneous changes.

The first major conclusion is that the market-adjusted $C A R$ findings are affected by the sample selection criteria effect. The abnormal returns associated with index revisions are attributable to changes in forecasts of growth in earnings per share by analysts and to temporary changes in liquidity costs. After adjusting for the sample selection criteria and liquidity cost effects, the findings support the price pressure

22. For the final sample plus low-priced stocks, the SAR also are significantly and positively related to expectations about firm prospects. 
TABLE 6. Cross-sectional Regressions of Average Daily Announcement Window Abnormal Returns and Various Explanatory Variables

\begin{tabular}{|c|c|c|c|c|c|c|c|c|c|}
\hline \multirow{2}{*}{$\begin{array}{l}\text { Regression } \\
\text { /statistic }\end{array}$} & \multicolumn{3}{|c|}{ Market adjusted $A R$} & \multicolumn{3}{|c|}{ Market model $A R$} & \multicolumn{3}{|c|}{ Standardized $A R$} \\
\hline & 1 & 2 & 3 & 4 & 5 & 6 & 7 & 8 & 9 \\
\hline Intercept & $\begin{array}{c}.084 \\
(.89)\end{array}$ & $\begin{array}{l}-.011 \\
(-.66)\end{array}$ & $\begin{array}{c}.018 \\
(.66)\end{array}$ & $\begin{array}{l}.014 \\
(.53)\end{array}$ & $\begin{array}{l}-.01 \\
(-.75)\end{array}$ & $\begin{array}{l}.013 \\
(1.2)\end{array}$ & $\begin{array}{l}-.10 \\
(-.15)\end{array}$ & $\begin{array}{l}.125 \\
(.39)\end{array}$ & $\begin{array}{l}2.46 \\
(.96)\end{array}$ \\
\hline$A N N$ & $\begin{array}{l}-.022 \\
(-1.27)\end{array}$ & $\begin{array}{c}.005 \\
(.35)\end{array}$ & $\begin{array}{r}-.027 \\
(-1.42)\end{array}$ & $\begin{array}{l}-.006 \\
(-.83)\end{array}$ & $\begin{array}{l}.006 \\
(.55)\end{array}$ & $\begin{array}{l}-.022 * * \\
(-2.07)\end{array}$ & $\begin{array}{l}-.569 * * \\
(-2.23)\end{array}$ & $\begin{array}{l}-.348 \\
(-.9)\end{array}$ & $\begin{array}{l}-.604 * * \\
(-2.2)\end{array}$ \\
\hline$A D D$ & $\begin{array}{l}.03 * * \\
(3.21)\end{array}$ & $\begin{array}{l}.031^{* *} \\
(2.49)\end{array}$ & $\begin{array}{l}.013 \\
(.68)\end{array}$ & $\begin{array}{l}.012^{* *} \\
(2.89)\end{array}$ & $\begin{array}{r}.015 \\
(1.85)\end{array}$ & $\begin{array}{l}.014 * * \\
(2.02)\end{array}$ & $\begin{array}{l}.748^{* *} \\
(3.54)\end{array}$ & $\begin{array}{l}.72 * * \\
(2.69)\end{array}$ & $\begin{array}{l}.733 * * \\
(3.4)\end{array}$ \\
\hline$M V C S$ & $\begin{array}{l}-.046 \\
(-.97)\end{array}$ & & & $\begin{array}{l}-.009 \\
(-.68)\end{array}$ & & & $\begin{array}{l}.141 \\
(.32)\end{array}$ & & \\
\hline$\# A N A L$ & $\begin{array}{r}.001 \\
(1.02)\end{array}$ & & & $\begin{array}{l}.000 \\
(.32)\end{array}$ & & & $\begin{array}{l}.024 \\
(.85)\end{array}$ & & \\
\hline$R V_{\mathrm{o}}$ & & & $\begin{array}{r}.006 \\
(1.61)\end{array}$ & & & $\begin{array}{c}.001 \\
(.76)\end{array}$ & & & $\begin{array}{l}.004 \\
(.07)\end{array}$ \\
\hline$C A R 240$ & & & $\begin{array}{l}-.003 \\
(-.32)\end{array}$ & & & $\begin{array}{c}-.012 \\
(-1.75)\end{array}$ & & & $\begin{array}{l}-.074 \\
(-.45)\end{array}$ \\
\hline$\triangle \% L R G$ & & & $\begin{array}{l}.101 \\
(.92)\end{array}$ & & & $\begin{array}{l}-.005 \\
(-.1)\end{array}$ & & & $\begin{array}{l}.8 \\
(.09)\end{array}$ \\
\hline$\Delta R S$ & & & $\begin{array}{l}-.354 \\
(-.85)\end{array}$ & & & $\begin{array}{r}-.274 \\
(-1.09)\end{array}$ & & & $\begin{array}{l}-4.16 \\
(-.92)\end{array}$ \\
\hline$\triangle \% A N A L$ & & $\begin{array}{l}.001 \\
(.25)\end{array}$ & & & $\begin{array}{l}-.003 \\
(-.67)\end{array}$ & & & $\begin{array}{l}.111 \\
(.8)\end{array}$ & \\
\hline
\end{tabular}




\section{TABLE 6. (Continued)}

\begin{tabular}{|c|c|c|c|c|c|c|c|c|c|}
\hline \multicolumn{2}{|l|}{$\Delta E s t g$} & \multicolumn{2}{|c|}{$\begin{array}{l}.102 * * \\
(3.79)\end{array}$} & \multicolumn{3}{|c|}{$\begin{array}{l}.056^{* *} \\
(2.7)\end{array}$} & \multicolumn{3}{|c|}{$\begin{array}{r}.647 \\
(1.61)\end{array}$} \\
\hline observations & 157 & 82 & 157 & 157 & 157 & 157 & 157 & 82 & 157 \\
\hline Adj. R-square & .046 & .09 & .054 & .028 & .074 & .08 & .1 & .067 & .087 \\
\hline
\end{tabular}

Note: Cross-sectional regression results for 2-day market-adjusted abnormal returns $(A R)$, first modified market model $A R$ and standardized $A R$ (or $S A R$ ) against ten independent variables for the pooled sample of 99 additions and 58 deletions are reported below. The $t$-values are reported in the parentheses below the coefficient estimates. $A N N$ is a dummy variable for whether the stock was involved in an annual or nonannual index revision ( 1 and 0 , respectively). $A D D$ is a dummy variable for whether the stock is an addition or a deletion ( 1 and 0 , respectively). MVCS is the natural $\log$ of the market value of common stock as of day $A D-1$. \#ANAL is the number of analysts following the stock as reported by $\mathrm{I} / \mathrm{B} / \mathrm{E} / \mathrm{S}$ as of day $A D-1 . R V_{0}$ is the contemporaneous cumulative trading volume of the stock relative to that for the market. CAR240 is cumulative marketadjusted abnormal return for the stock over the subsequent 240 trading days. $\Delta \% L R G$ is the change in the percentage of large trades. $\Delta R S$ is the change in the relative spread. $\triangle \% A N A L$ is the change in the number of analysts following the stock. $\triangle E s t g$ is the change in the consensus expected five-year growth in $E P S$ of analysts reporting to I/B/E/S. The last four independent variables, $\triangle \% L R G, \triangle R S, \triangle \% A N A L$ and $\triangle E s t g$, are calculated using the 60-day period starting two-days after the effective date $[E D+2, E D+61]$ relative to the 60 -day period ending the day before the announcement date $[A D-60, \mathrm{AD}-1]$. ** indicates significance at the 0.05 level. $T$-values are presented in the parentheses. 
hypothesis. The significant abnormal returns attributed to the announcements themselves appear to reverse post-announcement for both index additions and deletions. Although TSE300 additions and deletions are winners and losers prior to their selection, this behavior does not persist post-index change. This behavior is consistent with that previously identified in the Canadian markets for winners and losers by Kryzanowski and Zhang (1992).

The second major conclusion is that TSE300 indexers are aware that they are targets of speculators. Thus, TSE300 indexers generally concentrate their index revision-related trades on periods other than the effective date. The third major conclusion is that index additions and deletions are not causing changes in analyst following and behavior but that both are endogenous variables reacting to the same set of exogenous factors.

It would be interesting to determine if the price effects associated with the revision of various non-North-American market indexes is like that of the TSE300 or more like that of the S\&P500 or DJIA. One such index is the CAC index on the Paris Bourse, which also undergoes an annual revision that is similar to that for the TSE300.

\section{Appendix A}

\section{The Toronto Stock Exchange Index of 300 Stocks $^{23}$}

The TSE300 index was introduced in January 1977 to measure the overall performance of the Toronto Stock Exchange (TSE) and the movement of the Canadian economy. The index consists of 300 securities which belong to 14 industry groups and are primarily common stocks. The minimum eligibility criteria for inclusion in the index are: first, the company is incorporated in Canada or is substantially Canadian-owned; second, the security has been listed for more than one year; and third, the share's public quoted market value $(Q M V)$ must be greater than $\$ 100$ million, and must have traded at least 25,000 shares for a value of $\$ 1$ million during the past year. The $Q M V$ is calculated as the share price times the difference between the number of shares outstanding and the number of shares in control blocks of $20 \%$ or more. Thus, the index supposedly is tilted towards larger cap Canadian firms with higher trading volumes.

The Resource sector (metals and minerals, gold, oil, and gas) accounts for almost 30\% of the index over a time period (January 1984 through December

23. Drawn from various sources, such as Toronto Stock Exchange, 1988. Everything You Wanted to Know about the Toronto Stock Exchange 1988. 
1994) that includes the sample period studied herein. Other relatively large (10\% or more) industrial sectors represented in the index include industrial products, utilities and financial services. The composition of the index by industry has been relatively stable over the eleven-year period, 1984-1994. The largest weight reduction (increase) is 5.9\% (8.3\%) for metals and minerals (gold).

The TSE300 is similar to the S\&P500 in that it is revised periodically and unexpectedly as the result of mergers, acquisitions, other corporate reorganizations, and failures of an existing member. However, the TSE300 has at least four major differences from the S\&P500. First, no exchange-traded derivative products are available on the TSE300. Second, the TSE300 is also revised annually to reflect the changing investment opportunity set available to domestic investors. Thus, the resulting turnover in the TSE300 composition far exceeds that of the S\&P500. ${ }^{24}$ Third, the TSE300 is float- and not capitalization-weighted. Fourth, the TSE300 has sufficient small stock exposure to reasonably represent its market.

According to Baker (1990), the S\&P500 is much less representative of its local market in terms of stock coverage in number and in market value than similar indexes in the United Kingdom, Japan, and Canada. His ranking of the four indexes in decreasing order of domestic coverage in 1990 follows: the Japanese TOPIX index, which represents 1100 of about 2000 domestic stocks and about $92 \%$ of total domestic capitalization; the English FTA index, which represents 700 of about 1800 domestic stocks and about $89 \%$ of total domestic capitalization; the Canadian TSE300, which represents 300 of about 1000 domestic stocks and about $88 \%$ of total domestic capitalization; and the American S\&P500, which represents 500 of about 6000 domestic stocks and about $65 \%$ of total domestic capitalization. One of the interviewed indexers equated the TSE300 index to the WILSHIRE5000, and the TSE35 index to the S\&P500 index.

\section{Appendix B}

\section{Extent And Implementation of Equity Indexing in Canada ${ }^{25}$}

While Canada (like most non-U.S. countries) supposedly lags behind the United States in passive equity management, the evidence suggests that such

24. Baker (1990) estimates the turnover to be less than 5\% of the value of the S\&P500 annually. One of the interviewed indexers estimates the turnover to be over $7 \%$ of the value of the TSE300 annually.

25. This section is based on information elicited during interviews of indexers in March 1996. 
management has become important in Canadian markets, especially since 1989. Based on Benefit Canada's annual surveys of investment services, Williams (1993) noted that a nominal amount of index management was practiced by the 82 responding money managers who were responsible for $\$ 46.3$ billion in pension assets in 1983. In contrast, in 1993, 25 of the 125 responding money managers managed a combined $\$ 16$ billion of pension assets passively (total pension assets equalled $\$ 194$ billion). About 40 percent of these passively managed assets were domestic equities. In addition, a significant proportion of the $\$ 75$ billion in mutual funds and approximately $\$ 10$ billion in group RRSP assets were managed passively.

The indexers use either a full or partial replication management strategy. While full replication minimizes tracking error, the major argument against doing such is the difficulty in acquiring the smallest 200 TSE300 stocks in terms of capitalization at a reasonable cost. While derivatives are available on the TSE35, partial replication using such derivative products is possible but many indexers find that the TSE35 does not track the TSE300 well (Lett [1993]). Partial index replication using quadratic optimisation on, for example, the top 200 TSE300 stocks improves the tradeoff between tracking error and implementation cost in the Canadian market. Full replication indexers include BZW Barclays Global Investments and TD Asset Management, which manage over one billion dollars in indexed domestic equity, and the Ontario Teachers' Pension Plan Board, which manages over ten billion dollars in indexed domestic equity. Partial replication indexers of domestic equity include Garmaise Investment Technologies Inc.

When matching or mimicking a capitalization-weighted index, index rebalancing is necessary only when dividends are received or when changes in index membership occur. However, when the index provider (such as the TSE) manages the index proportions due to changes in float weights and index membership due to the annual revisions, changes in the relative proportions of the assets currently included or available for investment may require frequent significant rebalancings.

The interviewed indexers felt that it was much more difficult to practice in Canada. For example, since dividend reinvestment plans affect float and many TSE300 stocks have such plans, up to 1000 weight changes have to be made annually. Furthermore, while basket trading occurs primarily with investment dealers for the TSE35 on a regular basis and on custom baskets of the top 40 or 50 stocks in the TSE300 less frequently, no basket trading occurs for the TSE300. In contrast, trading of derivatives and baskets on the S\&P500 allow S\&P500 indexers to transact in a more timely and cost-efficient manner than TSE300 indexers.

The rebalancing strategies of the interviewed indexers are somewhat similar in that they depend on the perceived liquidity of the index additions and deletions. If possible, as is the case for annual changes, indexers generally start rebalancing prior to the effective date. Since they expect selling and buying 
pressure in the first few days post-announcement, they make such changes slowly and carefully. If the changed stocks lack liquidity, then the indexers start rebalancing more gradually, in lower trade sizes and earlier prior to the effective date, and continue after the effective date if needed. Although the market impact of transactions is of concern to all indexers, larger full replication indexers try to lessen the impact by transacting in an unpredictable manner. Electronic trading is used to facilitate and camouflage trades, and trade sizes below $\$ 10,000$ occur about five percent of the time.

Some indexers start to underweight a known deletion prior to the effective date by not reinvesting interim cash inflows into that stock. Proactive indexers trade in anticipation of annual index revision announcements when they are fairly certain about the identity of such changes.

\section{References}

Amihud, Y., and Mendelson, H. 1986. Asset pricing and the bid-ask spread. Journal of Financial Economics 17: 223-249.

Baker, E. D. 1990. Index fund management worldwide: How markets impact strategies. Canadian Investment Review 3 (November): 33-38.

Beneish, M. D., and Gardner, J. C. 1995. Information costs and liquidity effects from changes in the Dow Jones Industrial Average list. Journal of Financial and Quantitative Analysis 30(1): 135-157.

Beneish, M. D., and Whaley, R. E. 1996. An anatomy of the 'S\&P game': The effects of changing the rules. The Journal of Finance 51 (December): 19091930.

Boehmer, E.; Musumeci, J.; and Poulsen, A. B. 1991. Event-study methodology under conditions of event-induced variance. Journal of Financial Economics 30, 253-272.

Brennan, M. J., and Subrahmanyam, A. 1996. Market microstructure and asset pricing: On the compensation for illiquidity in stock returns. Journal of Financial Economics 41: 441-464.

Brown, S.; Goetzmann, W.; and Ross, S. 1995. Survival. Journal of Finance 50: 853-873.

Brown, S., and Pope, P. 1995. Post-earnings announcement drift: Market inefficiency or research design biases? Working Paper. New York: New York University.

Brown, S., and Warner, J. 1985. Using daily stock returns: The case of event studies. Journal of Financial Economics 14: 3-31.

Campbell, J. Y.; Lo, A. W.; and MacKinlay, A. C. 1997. The Econometrics of Financial Markets. Princeton, NJ: Princeton University Press.

Chung, R., and Kryzanowski, L. 1997a. Analyst following and market behaviour around TSE300 index revisions. In: SBF - Bourse de Paris (ed). Organization and Quality of Equity Markets. Paris: Presses Universitaires 
de France.

Chung, R., and Kryzanowski, L. 1997b. The cross-section of expected Canadian stock returns. Working Paper. Montreal, Canada: Concordia University.

Copeland, T., and Mayers, D. 1982. The Value Line enigma (1965-1978): A case study of performance evaluation issues. Journal of Financial Economics 10 (November): 289-321.

Dhillon, U., and Johnson, H. 1991. Changes in the Standard and Poor's 500 list. Journal of Business 64(1): 75-85.

Edmister, R. O.; Graham, A. S.; and Pirie, W. L. 1994. Excess returns of index replacement stocks: Evidence of liquidity and substitutability. The Journal of Financial Research 17 (Fall): 333-346.

Edmister, R. O.; Graham, A. S.; and Pirie, W. L. 1995. Trading cost expectations: Evidence from S\&P500 index replacement stock announcements. Working Paper. Oxford: University of Mississippi.

Fama, E. F., and French, K. R. 1992. The cross-section of expected stock returns. Journal of Finance 47 (June): 427-465.

Harris, L., and Gurel, E. 1986. Price and volume effects associated with changes in the S\&P500: New evidence for the existence of price pressure. Journal of Finance 41: 815-829.

Jain, P.C. 1987. The effect on stock price of inclusion in or exclusion from the S\&P500. Financial Analysts Journal 43: 58-65.

Kryzanowski, L., and To, M. C. 1982. On traditional market models as returngenerating models. The Financial Review 17 (September): 165-173.

Kryzanowski, L., and Zhang, H. 1992. The contrarian investment strategy does not work in Canadian markets. Journal of Financial and Quantitative Analysis 27 (September): 383-395.

Kryzanowski, L., and Zhang, H. 1996. Trading patterns of small and large traders around stock split ex-dates. Journal of Financial Research 19 (Spring): 75-90.

Leamer, E. E. 1983. Let's take the con out of econometrics. American Economic Review 75: 31-43.

Leamer, E. E. 1985. Sensitivity analysis would help. American Economic Review 75: 308-313.

Lett, T. 1993. A stock index in time. Benefits Canada (November): 85-86.

Lynch, A. W., and Mendenhall, R. R. 1997. New evidence on stock price effects associated with changes in the S\&P500 index. Journal of Business 70 (July): 351-383.

Pettengill, G. N.; Sundaram, S.; and Mahur, I. 1995. The conditional relation between beta and returns. Journal of Financial and Quantitative Analysis 30 (March): 101-115.

Pruitt, S.W., and Wei, K. C. J. 1989. Institutional ownership and changes in the S\&P500. Journal of Finance 44: 509-514.

Scholes, M., and Williams, J. T. 1977. Estimating betas from nonsynchronous 
data. Journal of Financial Economics 5(3): 309-327.

Shleifer, A. 1986. Do demand curves for stock slope down? Journal of Finance 41: 579-590.

Vijh, A. M. 1994. S\&P500 trading strategies and stock betas. The Review of Financial Studies 7 (Spring): 215-251.

Williams, P. 1993. Benefits Canada Top 40 - New frontiers. Benefits Canada (November): 29-35.

White, H. 1980. A heteroskedasticity-consistent covariance matrix and a direct test for heteroskedasticity. Econometrica 48: 817-838. 